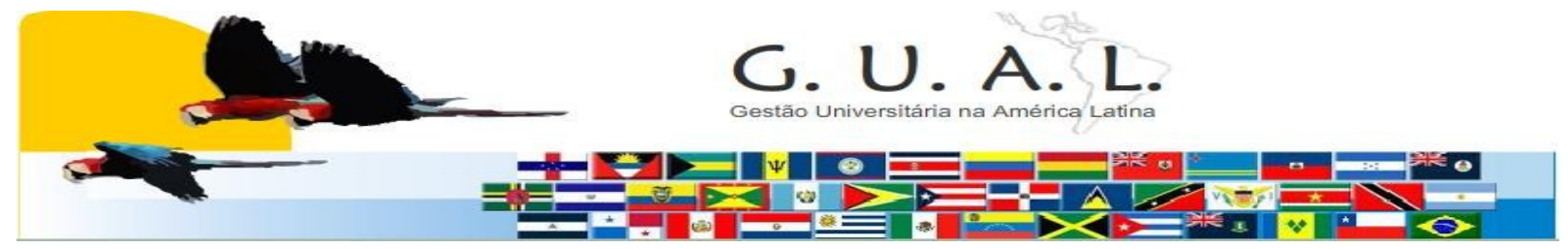

ISSN 1983-4535

\title{
ASPECTOS DA REESTRUTURAÇÃO DAS UNIVERSIDADES FEDERAIS POR MEIO DO REUNI - UM ESTUDO NO ESTADO DE SANTA CATARINA
}

\author{
Danilo de Melo Costa, Mestre \\ Centro Universitário UNA \\ danilo_mcosta@yahoo.com.br \\ Alexandre Marino Costa, Doutor \\ Universidade Federal de Santa Catarina - UFSC \\ marino@cse.ufsc.br
}

\author{
Cláudio José Amante, Doutor \\ Universidade Federal de Santa Catarina - UFSC \\ cjamante@reitoria.ufsc.br
}

Cláudio Heleno Pinto da Silva, Bacharel

Instituto Federal do Sudeste de Minas Gerais IFSMG

claudiohps@gmail.com

\section{RESUMO}

As Universidades Federais Brasileiras passam por uma grande transformação que ocorre por meio de sua reestruturação bem como sua expansão. Novas universidades e novos campi em universidades que já existiam estão agora presentes em todas as unidades da federação. No Estado de Santa Catarina, este crescimento esta pautado com a reestruturação da Universidade Federal de Santa Catarina, por meio do Reuni, e a criação da Universidade Federal da Fronteira Sul, fundada no âmbito do programa. Sendo assim, o presente artigo se propôs a analisar os principais aspectos desta reestruturação no Estado de Santa Catarina. Para tanto, realizou-se uma pesquisa exploratória e qualitativa. Para coleta e análise dos dados, foram utilizados desde relatórios do MEC, INEP, ANDIFES, leis e decretos, até materiais já publicados que tratavam do presente tema. Além do mais, foram realizadas entrevistas com os Reitores em exercício das instituições estudadas. Os resultados mostraram que a expansão das universidades federais tem, de fato, acontecido, e em Santa Catarina, este fenômeno se confirmou. Além da expansão do número de vagas, pôde-se constatar que o Reuni tem dado mais oportunidades as pessoas de classes economicamente desfavorecidas, sinalizando o início de uma importante democratização da educação superior no Brasil.

Palavras-chave: Reuni. UFSC. UFFS. Educação superior. Expansão. 


\section{INTRODUÇÃO}

A educação, em especial a educação superior, exerce grande influência na mobilidade social, como observado por Romanelli (1991) e Canuto (1987). A ascensão social, que norteia a realização pessoal de parte significativa da população, era e continua sendo o maior objetivo de quem busca as instituições de ensino superior. Desta forma, com o crescimento da economia, principalmente após a década de 1970, a procura pelo terceiro grau aumentou significativamente.

O Governo Federal, preocupado com o desenvolvimento da nação, passou a pautar sua análise ao indicador de jovens com idades entre 18 e 24 anos matriculados no ensino superior, pois esse grupo representa o principal "público alvo" das Instituições de Ensino Superior (UFCG, 2010). Em 1960, menos de 2\% da população entre essa faixa etária estava matriculada em instituições de ensino superior; em 1970, este índice passou para 5,2\% e, em 1975, alcançou o surpreendente índice de 11\% (SCHWARTZMAN, 2005).

Entretanto, este índice pouco se alterou nos anos seguintes. De acordo com os últimos dados disponíveis no Instituto Nacional de Estudos e Pesquisas Educacionais - INEP (2009), a taxa de alunos matriculados em instituições de ensino superior no ano de 2008 não ultrapassava a faixa de $13,7 \%$ entre os jovens com idade entre 18 e 24 anos ${ }^{\mathrm{i}}$. Se forem comparadas estas informações com a de outros países, tomando como referência o ano de 2004, pode-se observar que o Brasil ainda possui um longo caminho a percorrer. Na vizinha Argentina, este porcentual estava próximo de 40\%. Em outros países a diferença é ainda maior: Alemanha (50\%), França (60\%), EUA (80\%) e Canadá (quase 90\%) (GRACIANO; HADDAD, 2004).

Esse cenário perdura até os dias atuais. A procura por vagas em instituições públicas, além de financiamentos estudantis em instituições privadas, aumenta todos os anos, cabendo ao Governo Federal implantar medidas para atender a esta demanda.

Buscando responder à essas demandas, o Governo Federal lançou nos últimos anos uma série de programas que visam realizar esta expansão do ensino superior, não só quantitativamente, como também qualitativamente. Quatorze novas universidades públicas foram criadas, além de se realizar a expansão de novos campi nas universidades públicas já existentes, por meio do Programa de Apoio ao Plano de Reestruturação e Expansão das Universidades Federais - REUNI. O Programa Universidade para Todos - PROUNI - está 
sendo ampliado e agora atua juntamente ao Financiamento ao Estudante do Ensino Superior FIES-, aumentando assim a possibilidade de financiamento para os alunos. Estão sendo criados centenas de Institutos Federais de Ensino Superior - IFES - e também há um incremento da educação superior à distância, por meio da Universidade Aberta do Brasil UAB - com a criação de vários pólos em todo país, inclusive em regiões até então desprivilegiadas.

Partindo destas informações, o presente artigo aborda uma temática de grande relevância no cenário do desenvolvimento regional e nacional: a expansão e reestruturação da rede federal de educação superior no Estado de Santa Catarina, por meio da Universidade Federal de Santa Catarina (UFSC) e Universidade Federal da Fronteira Sul (UFFS), além das alterações no perfil sócio-econômico dos alunos em toda a região sul do Brasil.

\section{A EDUCAÇÃO SUPERIOR NO BRASIL E AS MUDANÇAS DE MARCO LEGAL}

Os próximos tópicos apresentam os principais marcos da educação superior no Brasil, desde seu surgimento, passando pelas leis de diretrizes e bases da educação, até as recentes políticas públicas do Governo Federal para a Educação Superior no país.

\subsection{O surgimento da educação superior no Brasil}

Desde o período colonial, há interesses e planejamentos para o surgimento da educação, inclusive a superior, no país. Conforme explica Loureiro (1986), com a chegada de Tomé de Souza no ano de 1549, os colonizadores passaram a se preocupar com a instrução na nova terra, iniciando então uma nova escola primária em Salvador, que com o tempo evoluiu e tornou-se o primeiro colégio com ensino secundário e algumas matérias superiores, como, por exemplo, letras e ciências (a segunda abrangendo Física, Metafísica, Lógica, Matemática e Ética). Entretanto, com a chegada da família real no ano de 1808, todas as escolas foram objetos de Cartas Régias, que justificavam suas criações, estabeleciam como deveriam ser financiadas e ainda contavam com instruções para o seu funcionamento. Tais providências regenciais tinham como objetivo elevar o nível em todos os campos intelectuais para aparelhar o Governo que aqui se estabelecia com a vinda da Família Real. Por esse aspecto, fica evidente a contribuição do Governo de Dom João VI para o início da educação superior no Brasil. 


\section{ASPECTOS DA REESTRUTURAÇÃO DAS UNIVERSIDADES FEDERAIS POR MEIO DO REUNI - UM ESTUDO NO ESTADO DE SANTA CATARINA}

No primeiro reinado brasileiro, sob o Governo de Dom Pedro I, havia a necessidade da criação de cursos de Direito, de vital importância para a consolidação da vida política e intelectual da recém Nação soberana. Foram fundados dois Cursos de Ciências Jurídicas e Sociais, um na Cidade de S. Paulo, e outro na de Olinda, segundo a Lei de 11 de agosto de 1827 (OAB, 2011). Já no segundo reinado, Dom Pedro II preocupava-se não só em manter e aperfeiçoar as já formadas instituições de Ensino Superior, como também em fundar novas. Durante o seu Governo, foram criadas, em 1875, a Escola de Minas de Ouro Preto; em 1880, a Escola de Belas Artes da Bahia e, em 1887, a Escola Politécnica da Bahia. Quando se proclamou a república, em 1889, o país já possuía, em São Paulo e Olinda, as escolas de Direito; na Bahia e no Rio de Janeiro, as escolas de Medicina e, em Ouro Preto, as escolas de Minas e Farmácia, todas financiadas pelo Governo (LOUREIRO, 1986).

Em consonância com os esforços da Monarquia, a república prosseguiu no financiamento da educação superior do país, fundando, entre os períodos de 1891 a 1937, 31 estabelecimentos de ensino superior (LOUREIRO, 1986).

\subsection{As leis de diretrizes e bases da educação (LDB) e as principais mudanças legais para a educação superior}

A partir da década de 1950, o parque industrial brasileiro cresceu e paulatinamente deixou de produzir itens apenas para substituir os importados. Caminhou-se para produção visando a atender o crescente mercado interno. Tal mudança no cenário industrial e tecnológico brasileiro exigiu trabalhadores mais qualificados, situação agravada com a internacionalização da economia e a necessidade das indústrias nacionais manterem-se competitivas frente aos baixos preços advindos dos produtos importados.

Como a importação de mão-de-obra para esses cargos que exigiam mais qualificação mais era onerosa e também um obstáculo para o desenvolvimento da nação, a alternativa do Governo junto aos grandes industriais foi voltar os olhos para o ensino. Desse modo, entre 1948 e 1961, foi amplamente discutida a Lei de Diretrizes e Bases da Educação, que seria implantada em 20 de Dezembro de 1961 (SILVA, 1991) e que atribuía ao Conselho Federal de Educação, por meio de medidas fiscalizadoras subordinadas ao Ministro da Educação, decidir sobre o funcionamento de cada instituição de ensino superior, federais ou privadas. Houve mudanças nos estatutos das Universidades públicas, que diversificaram seus

Rev. GUAL., Florianópolis, Edição especial 2011, p.01-24. 
cursos, criaram vários institutos de pesquisa, acrescentaram mais unidades docentes, implantaram novos programas, aumentaram tanto o corpo docente como o corpo discente e consequentemente passaram a receber mais recursos financeiros.

Entretanto, a adoção da Lei de Diretrizes e Bases não surtiu o efeito esperado em relação às atividades das instituições, sendo necessária a promulgação do Decreto de Lei $\mathrm{n}^{\mathrm{o}} 53$ de 18 de novembro de 1966, que fixou os princípios e normas de organização para as Universidades Federais. Esse decreto alterou os princípios que foram descritos de maneira superficial na Lei de Diretrizes e Bases, e assim estendeu a praticamente todas as universidades federais os princípios já vigentes na Lei no 3.998, de 15 de Dezembro de 1961 (TEIXEIRA, 1989).

Novamente, essa medida não foi suficientemente eficaz para promover a diversidade e a multifuncionalidade que as instituições de ensino superior deveriam ter para capacitar recursos humanos para a modernização do país, indicando a necessidade da reformulação do sistema de ensino superior vigente (CANUTO, 1987). Iniciou-se então um estudo da Reforma Universitária sob o enfoque da eficiência, modernização, flexibilidade, administrativa e, também, sob o enfoque da formação dos recursos humanos para auxiliar no desenvolvimento do país (LOUREIRO, 1986), resultando na Lei 539/69, complementada nos decretos 464/69 e 465/69, além de outros decretos que atribuíram à Universidade uma forma de excelência do ensino superior (multifuncional, polivalente, pautado no ensino e na pesquisa, mas pretendendo alocar também a formação profissional) e a faculdade isolada sendo admitida como exceção.

Essas reformas buscavam compatibilizar a Universidade com o mercado de trabalho, mas sem tornar-se puramente tecnocrata. No entanto, o Brasil vivia a era da Ditadura Militar (1964 a 1985) e, mesmo considerando a educação como fator importante para o desenvolvimento, o Governo brasileiro enfrentava problemas relacionados à escassez de capital monetário, tendo em vista que esse recurso era empregado principalmente em setores de acumulação de capital (como agricultura e indústria). Por esse motivo, o favorecimento ao ensino superior privado foi a alternativa encontrada na época para alavancar o desenvolvimento do capital humano da nação e, consequentemente, toda nação.

Esse favorecimento foi de extrema importância para o desenvolvimento e expansão do ensino superior privado, pois facilitou e permitiu a criação de instituições de 
ensino superior com fins lucrativos e trouxe empreendedores para o setor, na busca de retornos financeiros satisfatórios. Entretanto, devido aos incentivos recebidos, o número de instituições privadas cresceu vertiginosamente e de uma forma meramente quantitativa. Para conter esse crescimento indesejado, no final da década de 1970, o Governo Federal fechou as portas para a autorização de novas instituições de ensino no país, algo que perdurou até a década de 1990 (CANUTO, 1987).

Na década de 1990, uma mudança de marco legal transformou profundamente o setor de ensino superior no país. Entre várias inovações, a implantação da Lei de Diretrizes e Base da Educação em 1996 (LDB/96) - Lei 9.394/96 - definiu significativas mudanças para o financiamento do ensino superior público e privado. Ao ensino superior público, a LDB assegurou uma autonomia até então inédita para as Universidades. Essa autonomia consistia em: desenvolver e aplicar seu próprio orçamento; reavaliar operações de crédito; receber doações, heranças, legados e obter cooperação financeira de parcerias público-privadas, tornando legítima a busca pelas mais diferentes fontes de financiamento, sem se isentar da responsabilidade da distribuição de recursos para as instituições.

Segundo a LDB/96: “Caberá a União assegurar, anualmente, em seu Orçamento Geral, recursos suficientes para manutenção e desenvolvimento das instituições de educação superior por ela mantidas." (art. 55 da LDB, Lei 9.394, de 23 de Dezembro de 1996). Ficou também instituída, apenas às Universidades, a obrigação da indissociabilidade do ensino, pesquisa e extensão, influenciando a diminuição do número de Universidades, pois, além de precisarem dedicar-se às atividades de ensino, pesquisa e extensão, para obter (e manter) o título de Universidade, era necessário $1 / 3$ de professores em regime de tempo integral e com titulação de Mestrado ou Doutorado (art. 52 da LDB, Lei 9.394, de 23 de Dezembro de 1996). Instituições que não se adequassem a essas medidas seriam então organizadas como Centros Universitários.

Finalmente, como uma de suas principais iniciativas, a LBD de 1996 determinou que a União encaminhasse, ao Congresso Nacional, o Plano Nacional da Educação (PNE), com diretrizes e metas para os dez anos seguintes em consonância com a Declaração Mundial sobre Educação para todos. 


\subsection{As políticas públicas do governo federal para a educação superior}

As recentes políticas públicas do Governo Federal para a Educação possuem dois importantes marcos: o lançamento do Plano Nacional da Educação, em 2001; e a criação do Plano de Desenvolvimento da Educação, em 2007.

\subsubsection{O Plano Nacional da Educação}

Em 9 de janeiro de 2001, foi sancionada a Lei $n^{\circ}$ 10.172, que estabelece o Plano Nacional de Educação, PNE. O PNE foi assentado sobre três ideias chave:

1) a educação como direito de todos;

2) a educação como fator de desenvolvimento social e econômico do país; e

3) a educação como instrumento de combate à pobreza e de inclusão social (BRASIL, 2001).

Para o Ensino Superior, suas principais premissas foram:

1) fornecer, até o final da década, a oferta da educação superior para, pelo menos, $30 \%$ dos jovens entre 18 a 24 anos;

2) ampliar a oferta do ensino público de modo a assegurar uma proporção de, pelo menos, $40 \%$ do total das vagas;

3) estabelecer um amplo sistema de educação à distância;

4) estabelecer um sistema de recredenciamento das instituições, garantindo assim a qualidade;

5) diversificar a oferta de ensino, investindo em cursos noturnos, modulares e sequenciais (BRASIL, 2001).

Para PINTO (2002), o PNE assumiu responsabilidades financeiras que não condiziam com a realidade do país. De acordo com o autor, na época de sua promulgação, o investimento do PIB na educação era na ordem de 4\%. Em contrapartida, para se alcançar as metas do PNE, seria necessário um investimento na ordem de $10 \%$ do PIB, o que certamente configurar-se-ia como um grande desafio. Essas características fizeram com que fosse necessário estudar mais profundamente uma reconfiguração do ensino superior no País, embasando-se em um documento intitulado Plano de Desenvolvimento da Educação (PDE). 


\subsubsection{O Plano de Desenvolvimento da Educação}

O Plano de Desenvolvimento da Educação (PDE) está ordenado segundo a lógica do arranjo educativo, local, regional ou nacional. Seus 40 programas são classificados de acordo com quatro eixos de referência: educação básica, educação superior, educação profissional e alfabetização. Dentro dos limites traçados para esse artigo, os programas analisados foram os referentes à educação superior.

O Ministério da Educação observa que a educação superior deve ser analisada por meio dos seguintes princípios que se complementam: i) expansão da oferta de vagas; ii) garantia de qualidade; iii) promoção de inclusão social pela educação; iv) distribuição territorial e v) desenvolvimento econômico e social (BRASIL, 2007).

Após definição destas premissas, criando novos programas e utilizando-se de programas já existentes, o PDE visou atender com qualidade a essa demanda de expansão. Foram criadas quatorze novas Universidades públicas; promoveu-se a expansão de novos campi nas Universidades públicas já existentes por meio do REUNI; estão sendo criadas centenas de Institutos Federais de Educação Superior - Ifes; houve a ampliação da ação do Programa Universidade para Todos - ProUni - passando a atuar juntamente com o Financiamento Estudantil - FIES; e foi realizado um incremento da educação superior à distância, por meio da Universidade Aberta do Brasil - UAB, com a criação de dezenas de pólos em todo país (BRASIL, 2007b).

Os próximos tópicos pretendem analisar o desenvolvimento e a expansão das Universidades Federais, com destaque para as universidades federais catarinenses, por meio do Programa de Expansão e Reestruturação das Universidades Federais (REUNI), além de apresentar as alterações no perfil sócio-econômico dos alunos da região sul após a implantação do programa.

\section{METODOLOGIA}

Em função dos objetivos desta pesquisa, o trabalho foi concebido como uma pesquisa exploratória. Segundo Gil (1995), as pesquisas exploratórias são desenvolvidas com objetivo de proporcionar visão geral, de tipo aproximativo. Tal estudo se caracteriza como exploratório por buscar se aprofundar nos planos do Governo Federal para a reestruturação das Universidades Federais, com foco no Estado de Santa Catarina, e o estabelecimento de 
relações com outras informações, como o perfil sócio-econômico dos alunos da rede federal na região sul.

$\mathrm{O}$ artigo possui um caráter qualitativo, mesmo que utilizando dados estatísticos e dados numéricos disponíveis no Censo da Educação Superior e no Ministério da Educação para interpretar o objeto em termos do seu significado e entender a natureza de um fenômeno social (RICHARDSON, 1999).

A coleta de dados foi estruturada por meio de fonte primaria ou pesquisa documental. Como fontes primárias foram utilizados documentos tais como: relatórios de gestão do Governo Federal referente ao programa REUNI; decretos; relatórios de gestão; dados referentes ao Reuni na UFSC e relatórios de gestão da UFFS, além do plano de reestruturação das universidades pesquisadas; dados do INEP e relatórios do Ministério da Educação; além do último relatório a respeito do Perfil Socioeconômico e Cultural dos Estudantes de Graduação das Universidades Federais Brasileiras, publicado pela Associação Nacional dos Dirigentes das Instituições Federais de Ensino Superior (ANDIFES).

A pesquisa bibliográfica ou de fonte secundária também foi utilizada. Tal pesquisa se deu por meio da coleta de material já elaborado e publicado sobre o tema da pesquisa, como publicações avulsas, boletins, jornais, revistas, livros, artigos, dissertações e teses.

Finalmente, realizou-se entrevistas com os Reitores em exercícios da Universidade Federal de Santa Catarina e da Universidade Federal da Fronteira Sul, visando compreender os resultados observados por intermédio do Reuni, conforme Quadro 1:

\begin{tabular}{|c|c|c|c|c|}
\hline Local & Função & Cidade & Dia & Horário \\
\hline $\begin{array}{c}\text { Universidade Federal de } \\
\text { Santa Catarina (UFSC) }\end{array}$ & $\begin{array}{c}\text { Vice-Reitor } \\
\text { UFSC }\end{array}$ & Florianópolis & $03 / 11 / 2010$ & $16: 00$ às 17:00 \\
\hline $\begin{array}{c}\text { Universidade Federal da } \\
\text { Fronteira Sul (UFFS) }\end{array}$ & Reitor UFFS & Chapecó & $05 / 10 / 2010$ & $09: 00$ às 10:00 \\
\hline
\end{tabular}

Quadro 1 Entrevistados.

Fonte: Elaborado pelo autor.

A análise dos dados foi estruturada, conforme Yin (1989), de maneira em que a mesma consiste na compreensão dos dados no sentido de validar ou refutar os objetivos iniciais do estudo. Partindo dessa premissa, após a coleta dos dados, houve uma compilação 
das informações coletadas selecionando as de maior interesse e posteriormente foi realizado o registro dos dados por meio de alocação em planilhas eletrônicas.

Posteriormente foi realizada uma análise dos dados da pesquisa, por meio de cruzamento das informações registradas visando identificar os principais aspectos do Reuni a nível nacional e os reflexos observados no Estado de Santa Catarina. Além disso, buscou-se compreender as alterações no perfil sócio-econômico dos alunos, sobretudo na região sul, após a implantação do programa, conforme na assertiva de Selltiz et. al. (1974) que defende que o objetivo da análise dos dados é sintetizar as informações completadas, de maneira que as informações viabilizem respostas aos questionamentos da pesquisa em foco.

\section{REUNI: ASPECTOS NACIONAIS E REGIONAIS E A INFLUÊNCA NO PERFIL SOCIOECONÔMICO DOS ALUNOS NAS UNIVERSIDADES}

As próximas secções apresentam o Reuni, desde seu surgimento, até as expectativas do programa a Nível Nacional. Será apresentada a influência do Reuni na Universidade Federal de Santa Catarina e, posteriormente, na Universidade Federal da Fronteira Sul, que é uma universidade fundada no âmbito do Reuni. Finalmente, será demonstrada a influência do Reuni no perfil Sócio-Econômico dos estudantes de graduação, com foco na Região Sul.

\subsection{Surgimento}

A partir do segundo semestre de 2006, começou-se uma discussão sobre o ensino ministrado nas universidades públicas brasileiras, em que a partir de dados estatísticos, análises e reflexões, concluiu-se que deveriam existir mais vagas no ensino superior público, além de trabalhar para redução das taxas de evasão.

Com base neste prognóstico, o professor Naomar Monteiro de Almeida Filho, até então reitor da Universidade Federal da Bahia, apresentou uma proposta visando reverter tal quadro. Esta proposta se chamava "Universidade Nova". A partir de então, entre os anos de 2006 e 2007, foi discutido de maneira reservada um documento não-oficial que recebera o nome de Programa de Apoio a Planos de Reestruturação e Expansão das Universidades Federais. 
Após o MEC apresentar e debater tal documento com várias instituições, com destaque para a Associação Nacional dos Dirigentes das Instituições Federais de Ensino Superior (ANDIFES), definiu-se a versão final, mantendo basicamente os mesmos princípios dos documentos anteriores (LÉDA; MANCEBO, 2009).

Desta forma, em 24 de abril de 2007, por meio do Decreto $\mathrm{n}^{\circ} 6.096$, surge o Programa de Apoio a Planos de Reestruturação e Expansão das Universidades Federais (REUNI), como uma das ações integrantes do Plano de Desenvolvimento da Educação (PDE), em reconhecimento ao papel estratégico das universidades federais para o desenvolvimento econômico e social, tendo como principal objetivo o aumento das vagas de ingresso e a redução das taxas de evasão nos cursos presenciais de graduação (BRASIL, 2007).

Para se alcançar o objetivo proposto, o programa se amparou em seis importantes diretrizes:

a) a diminuição da taxa de evasão, ocupação das vagas ociosas além do aumento da vaga de ingresso, principalmente no período noturno;

b) aumento da mobilidade estudantil;

c) revisão de toda estrutura acadêmica;

d) variação das modalidades de graduação;

e) acréscimo de políticas de inclusão e assistência estudantil; e

f) trabalho conjunto entre a graduação e a pós-graduação e entre a educação superior e a educação básica (BRASIL, 2007).

\subsection{Expectativas do REUNI a nível Nacional}

Com duração prevista para 5 anos, o REUNI pretende distribuir mais de 2 bilhões de reais entre as Universidades Federais, conforme pode ser observado no Gráfico 1. Em compensação, as universidades precisarão melhorar em vários aspectos, como nos recursos humanos, estrutura física e, principalmente, na qualidade dos cursos de graduação ofertados. Ao final destes 5 anos, o REUNI pretende melhorar os indicadores das instituições federais de educação superior. O objetivo é que esta expansão ocorra permitindo um acesso democrático ao ensino superior público, aumentando o contingente de estudantes menos favorecidos economicamente. Além disso, o governo pretende alcançar uma taxa de conclusão média de $90 \%$ na graduação presencial, uma correspondência de 18 alunos para cada professor nas salas de aula e um aumento mínimo de 20\% nas matrículas de graduação (MEC, 2010). 


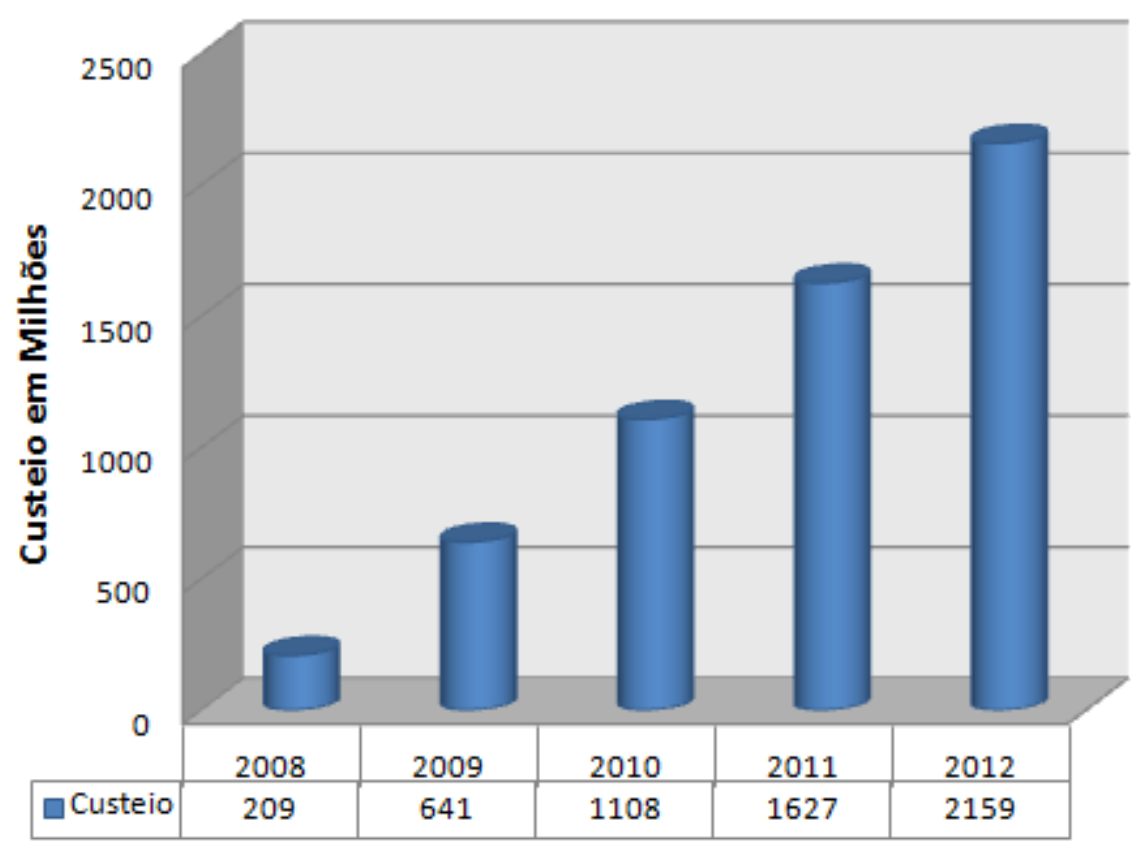

Gráfico 1 REUNI - Custeio em Milhões de reais.

Fonte: MEC (2010).

Como resultado do grande investimento que será realizado, o Governo Federal espera aumentar o número de cursos de graduação presencial nas universidades públicas para 3.601 em 2012, e consequentemente, o número de vagas para 227.260 na mesma data. Em relação aos cursos noturnos, os objetivos são elevá-los para 1.299 cursos e as vagas para 79.215 em 2012. Além disso, há uma grande preocupação em relação à formação de professores para a educação básica, e por este motivo, o governo espera aumentar os cursos de licenciatura para 1.198 e as vagas para 79.191 (MEC, 2010).

Para atingir esses objetivos, foi necessária a ampliação do número de universidades federais, de campi e interiorização das instituições para atender a uma maior parcela da população. Este processo vem acontecendo desde 2003, quando se deu início aos primeiros processos para a interiorização dos Campi. A partir de então, pretende-se aumentar o número de municípios atendidos pelas universidades que a princípio irá aumentar de 114 para 237 até o final de 2011. Além disso, desde o início do processo de expansão foram criadas 14 novas universidades, conforme pode ser observado no Gráfico 2. 


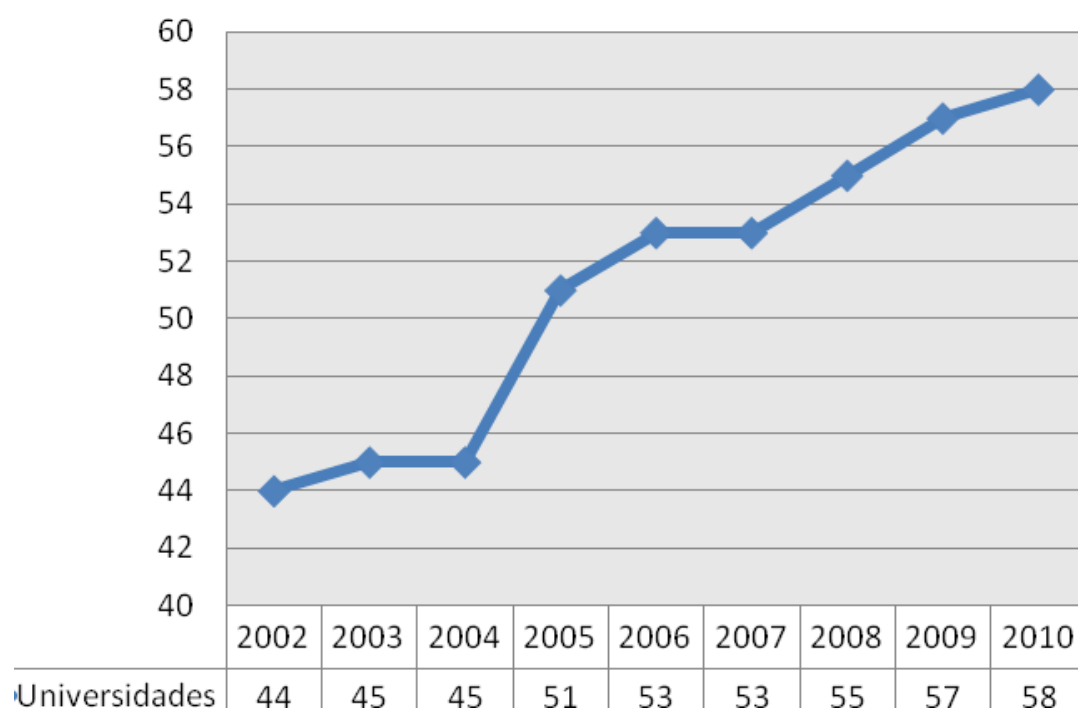

Gráfico 2 Expansão das Universidades Federais - 2002 à 2010.

Fonte: MEC (2010)

São elas: Universidade Federal do Vale do São Francisco (UNIVASF); Universidade Federal Rural do Semi-Árido (UFERSA); Universidade Federal do ABC (UFABC); Universidade Federal do Triângulo Mineiro (UFTM); Universidade Federal da Grande Dourados (UFGD); Universidade Federal do Vale do Jequitinhonha e Mucuri (UFVJM); Universidade Tecnológica Federal do Paraná (UTFPR); Universidade Federal do Pampa (Unipampa); Universidade Federal do Recôncavo da Bahia (UFRB); Universidade Federal de Ciências da Saúde de Porto Alegre (UFCSPA); Universidade Federal da Fronteira Sul (UFFS); Universidade Federal do Oeste do Pará (UFOPA); Universidade Federal da Integração Latino-Americana (UNILA); e Universidade Luso-Afro-Brasileira (UNILAB) (MEC, 2010):

O processo de Reestruturação e Expansão teve um amplo reflexo no Estado de Santa Catarina, por meio da Reestruturação da Universidade Federal de Santa Catarina e da criação da Universidade Federal da Fronteira Sul, conforme explanado a seguir.

\subsection{A influência do REUNI na Universidade Federal de Santa Catarina}

Fundada em 1960, e completando 51 anos no ano de 2011, a Universidade Federal de Santa Catarina é uma instituição que tem por finalidade: 
Produzir, sistematizar e socializar o saber filosófico, científico, artístico e tecnológico, ampliando e aprofundando a formação do ser humano para o exercício profissional, a reflexão crítica, solidariedade nacional e internacional, na perspectiva da construção de uma sociedade justa e democrática e na defesa da qualidade de vida. (UFSC, 2010b)

A UFSC aderiu ao Reuni na primeira chamada do programa, dia 29 de Outubro de 2007, para implantação no $1^{\circ}$ semestre 2008.

Para a UFSC a adesão ao REUNI foi vantajosa, com destaque para a interiorização dos Campi, uma importante iniciativa para o desenvolvimento regional, trazendo importantes melhorias para as regiões em que as instituições estão inseridas.

Segundo o Vice-Reitor da UFSC, o processo de interiorização dos Campi permitiu uma maior interação da universidade com a sociedade, sobretudo nas cidades pólos, que receberam os novos campi. Essa interação melhorou substancialmente a imagem da universidade junto à sociedade, que passou a percebê-la não apenas como uma universidade litoralizada e da capital, e sim como uma universidade pertencente a todo o estado.

Com esta interiorização nos próximos anos, a expectativa é que a credibilidade da instituição aumente na medida em que mais estudantes residentes nessas regiões concluam seus cursos superiores, demonstrando que a educação dos novos campi, e consequentemente da Universidade é de qualidade e que o processo para estas implantações está de acordo com o desenvolvimento do estado e das regiões ao qual as instituições estão inseridas.

Com a interiorização, tanto o meio-oeste, como o norte e o sul, receberam extensões da UFSC, além é claro, do grande auxílio para o desenvolvimento do extremo oeste, por meio da instalação da nova Universidade Federal da Fronteira Sul, que juntamente com a UFSC, conseguiu abranger as principais regiões do estado e terão papel chave no progresso do estado nos próximos anos. Entretanto, é percebido um certo vazio neste aspecto no que se refere ao Vale do Itajaí, havendo inclusive uma tentativa de solicitação de federalização por parte da Fundação Universidade Regional de Blumenau (FURB). De qualquer maneira, se considera que foi feita uma distribuição racional por todo o estado.

Ao aderir ao Programa Reuni, visando sua expansão e reestruturação, a Universidade Federal de Santa Catarina traçou uma meta de ampliação do número de vagas e, conseqüentemente, de alunos matriculados para todos os cursos, além da criação de cursos 
novos. Juntamente com a interiorização dos Campi, a ampliação de vagas e de alunos matriculados, tem se configurado como uma das principais ações da UFSC.

No que se refere ao repasse dos recursos visando à ampliação dos cursos, houve alterações estruturais positivas na instituição, já que os valores antes trabalhados, no momento da pactuação do REUNI, eram diferentes dos atuais.

Especificamente em relação à ampliação de vagas e cursos, quando o plano de adesão da UFSC foi enviado ao MEC, ao final de 2007 e início de 2008, houve o estabelecimento de algumas metas, conforme Quadro 2 e Quadro 3:

\begin{tabular}{|c|c|c|c|c|c|c|}
\hline $\begin{array}{c}\text { Total de Cursos } \\
\text { Novos }\end{array}$ & $\mathbf{2 0 0 8}$ & $\mathbf{2 0 0 9}$ & $\mathbf{2 0 1 0}$ & $\mathbf{2 0 1 1}$ & Noturno & Diurno \\
\cline { 2 - 7 } & 3 & 12 & 4 & 1 & 6 & 14 \\
\hline Sub-Total & \multicolumn{7}{|c|}{1.360 vagas } \\
\hline Total Geral & \multicolumn{7}{|c|}{} \\
\hline
\end{tabular}

Quadro 2 Total de Cursos Novos - Adesão ao Reuni.

Fonte: UFSC (2010, p. 4)

\begin{tabular}{|c|c|c|}
\hline Ampliação de vagas & Noturno & Diurno \\
\hline 2008 & 0 & 175 \\
\hline 2009 & 315 & 630 \\
\hline 2010 & 60 & 150 \\
\hline 2011 & 0 & 30 \\
\hline 2012 & 0 & 0 \\
\hline Sub-Total & 375 & 985 \\
\hline Total Geral & \multicolumn{2}{|c|}{1.360 vagas } \\
\hline
\end{tabular}

Quadro 3 Ampliação do número de vagas -Adesão ao Reuni.

Fonte: UFSC (2010, p.4)

Entretanto, realizando uma comparação entre o planejamento enviado pela UFSC no final de 2007 para adesão ao Reuni (Quadro 2 e Quadro 3) com os últimos dados do relatório de acompanhamento do Reuni disponibilizados pela Andifes (Quadro 4 e Quadro 5), observa-se que a UFSC superou a meta pré-estabelecida para a criação de novas vagas:

Rev. GUAL., Florianópolis, Edição especial 2011, p.01-24. 


\begin{tabular}{|c|c|c|c|}
\hline Ano & Geral & Noturna & Licenciatura \\
\hline 2006 & 3920 & 925 & 1150 \\
\hline 2007 & 3920 & 925 & 1150 \\
\hline 2008 & 4095 & 925 & 1190 \\
\hline 2009 & 5221 & 1130 & 1294 \\
\hline 2010 & 6021 & 1345 & 1264 \\
\hline Total de Vagas Novas & 2101 & 420 & 114 \\
\hline
\end{tabular}

Quadro 4 Ampliação do número de vagas -Relatório ANDIFES. Fonte: ANDIFES (2010, p.175)

\begin{tabular}{|c|c|c|c|}
\hline Ano & Geral & Noturna & Licenciatura \\
\hline 2006 & 62 & 14 & 23 \\
\hline 2007 & 62 & 14 & 23 \\
\hline 2008 & 65 & 15 & 23 \\
\hline 2009 & 70 & 19 & 25 \\
\hline 2010 & 82 & 20 & 23 \\
\hline Total de Cursos Novos & 20 & 7 & 0 \\
\hline
\end{tabular}

Quadro 5 Evolução do número de cursos - Relatório ANDIFES.

Fonte: ANDIFES (2010, p.175)

Estes dados demonstram que, nos aspectos quantitativos, a adesão do Reuni tem trazido resultados positivos para a Universidade Federal de Santa Catarina.

\subsection{Universidade Federal da Fronteira Sul - uma universidade fundada no âmbito do Reuni}

Criada em 15 de Setembro de 2009, por meio da Lei 12.012, a UFFS é uma instituição de ensino superior pública e popular, que abrange os 396 municípios da Mesorregião Fronteira Mercosul - Sudoeste do Paraná, Oeste de Santa Catarina e Noroeste do Rio Grande do Sul e tem por missão:

1. Assegurar o acesso à educação superior como fator decisivo para o desenvolvimento da região da fronteira sul, a qualificação profissional e a inclusão social;

2. Desenvolver atividades de ensino, pesquisa e extensão buscando a interação e a integração das cidades e estados que compõem a grande fronteira do Mercosul e seu entorno;

3. Promover o desenvolvimento regional integrado - condição essencial para a garantia da permanência dos cidadãos graduados na região da fronteira sul e a reversão do processo de litoralização hoje em curso. (UFFS, 2010)

Rev. GUAL., Florianópolis, Edição especial 2011, p.01-24. 
A Universidade Federal da Fronteira Sul teve como instituição matriz a Universidade Federal de Santa Catarina, tendo seu projeto e concepção desenvolvidos dentro desta universidade. Um dos principais Institutos de Pesquisa responsáveis por esse desenvolvimento foi o Instituto de Pesquisa e Estudos em Administração Universitária, o INPEAU, que teve o papel de incubador da UFFS. O INPEAU (anteriormente denominado NUPEAU) foi criado em 1988 e tem como objetivo: “(...) gerar, disseminar e preservar o conhecimento científico e tecnológico desenvolvido na área de Administração Universitária, visando a construção de um moderno sistema de educação superior (INPEAU, 2011).”

Quando se analisa o papel da UFFS dentro do Reuni, constata-se que oficialmente a UFFS não faz parte do programa. Entretanto, pode-se considerar que ela está inserida na filosofia do programa, quando se considera que o REUNI foi instituido com o objetivo de criar novas Universidades e campi no interior do país, visando a reestruturaçao das universidades já existentes, a expansão das suas atividades, saindo estritamente das capitais, pois as universidades federais, com excecao do estado de Minas Gerais, eram as categorias administrativas federais menos interiorizadas, diferentemente das universidades estaduais, comunitárias e até as privadas com fins lucrativos.

A UFFS, por este motivo, pode ser considerada uma universidade que faz parte dos mesmos princípios de democratização ao qual fazem parte as universidades participantes do REUNI, por trabalhar com a idéia de uma estrutura multi-campi e interiorizada.

Outro aspecto que faz com que a UFFS esteja ligada aos ideais do Reuni é a preocupação aparente com a reestruturação dos cursos tradicionais. A interdisciplinaridade foi um fator considerado quando se buscou definir novas ênfases para os cursos, como por exemplo o curso de Agronomia com ênfase em Agro-Ecologia, o curso de Engenharia Ambiental combinado com o curso de Energias Renováveis e o curso de Ciências, combinando Química, Física e Biologia. Essa nova perspectiva atua conjuntamente com a política de formação de professores para a educação básica, uma das maiores preocupações do Governo Federal atualmente.

Por se tratar de uma universidade recentemente inaugurada, sob o âmbito do Reuni e de acordo com as principais políticas do governo federal, a ampliação do número de vagas é uma preocupação oriunda da gestão federal e que perpassa todos os objetivos da universidade. 
Neste sentido, a Universidade Federal da Fronteira Sul precisa avançar em termos orçamentários. No entanto, o Governo Federal reconhece a importância da instituição para o desenvolvimento da região e repassa os recursos para o cumprimento das funções da universidade, conforme o planejado. Logo, o cenário de expansão para os próximos anos se faz otimista.

No que se refere a ocupação das vagas disponibilizadas, por motivo da Universidade Federal da Fronteira Sul ser uma universidade nova e estar inserida em uma região historicamente excluída do direito ao ensino superior, sobretudo em relação ao ensino superior público, foi necessário um grande esforço por meio de várias chamadas para se ocupar as vagas existentes na universidade.

Neste sentido, a UFFS conseguiu atingir um satisfatório índice de preenchimento de suas vagas disponibilizadas. Das 2160 vagas existentes na Universidade, 2035 foram preenchidas e são utilizadas até então por estudantes que são oriundos, em sua maioria, de ensino público. Além disso, grande parte destes alunos são da própria região da Fronteira-Sul, o que culmina com os objetivos de auxilio no progresso da região contemplada com a UFFS.

A decisão de se iniciar as atividades em Março de 2010 oferecendo 2160 vagas se deu pela importância de tentar atender principalmente a população local (mesmo sendo aberta para todo Brasil). A expectativa é que em 4 anos a universidade tenha 8.640 alunos matriculados no âmbito da graduação, além de cursos de Mestrado e Doutorado. Entretanto, vale a pena ressaltar a preocupação da Universidade em garantir este acesso sobretudo para a população local, algo que tem sido atingido quando se observa os últimos relatórios da universidade.

\subsection{A influência do Reuni no perfil socioeconômico dos estudantes de graduação na região sul}

O REUNI, conforme exposto anteriormente, fez com que o acesso à educação superior nas instituições públicas federais aumentasse consideravelmente. Além disso, de acordo com os últimos dados publicados pela ANDIFES, no relatório do Perfil Socioeconômico e Cultural dos Estudantes de Graduação das Universidades Federais Brasileiras, tal programa serviu ainda para aumentar o acesso de estudantes inseridos em classes econômicas mais baixas, as chamadas classes C, D e E, como mostra o Quadro 6. 


\begin{tabular}{|l|l|l|l|l|l|l|l|l|l|}
\hline \multirow{2}{*}{ Nacional } & A1 & A2 & B1 & B2 & C1 & C2 & D & E & C D e E \\
\cline { 2 - 9 } & 2,35 & 12,90 & 17,58 & 23,49 & 19,59 & 14,01 & 9,60 & 0,47 & 43,76 \\
\hline Sul & 2,39 & 14,38 & 21,39 & 27,99 & 20,35 & 10,14 & 3,29 & 0,06 & 33,84 \\
\hline
\end{tabular}

Quadro 6 Distribuição percentual dos estudantes das Universidades Federais por classes econômicas Fonte: ANDIFES (2011, p.19), Adaptado pelo autor.

Além disso, observa-se o aumento do acesso dos estudantes que cursaram o ensino médio em escolas públicas. Nesse cenário, se destaca a região sul, que tem mais de $50 \%$ dos estudantes nas universidades federais provenientes de escolas públicas (ficando atrás apenas da Região Norte, que possui 71,47\%), conforme o Quadro 7:

\begin{tabular}{|c|c|c|c|c|}
\hline & \multicolumn{4}{|c|}{$\%$} \\
\cline { 2 - 5 } & $\begin{array}{c}\text { Somente } \\
\text { Escola Pública }\end{array}$ & $\begin{array}{c}\text { Maior parte } \\
\text { Escola Pública }\end{array}$ & $\begin{array}{c}\text { Maior Parte Escola } \\
\text { Particular }\end{array}$ & $\begin{array}{c}\text { Somente Escola } \\
\text { Particular }\end{array}$ \\
\hline Nacional & 44,81 & 5,58 & 7,24 & 42,36 \\
\hline Nordeste & 41,35 & 6,07 & 7,22 & 45,35 \\
\hline Norte & 71,47 & 6,80 & 5,55 & 16,18 \\
\hline Sudeste & 37,02 & 4,42 & 8,05 & 50,51 \\
\hline Sul & 50,57 & 5,62 & 6,09 & 37,72 \\
\hline Centro-Oeste & 40,69 & 6,22 & 8,55 & 44,54 \\
\hline
\end{tabular}

Quadro 7 Tipo de escola em que cursou o ensino médio

Fonte: ANDIFES (2011, p.30).

Estes dados comprovam o a eficácia do REUNI, no que diz respeito à democratização do ensino superior, com reflexos na região sul. Quando se analisa os dados em função dos anos correntes, comparando-os com outros relatórios da ANDIFES, o aumento da porcentagem de alunos vindos da escola pública é latente , conforme comprova o Quadro 8 .

\begin{tabular}{|c|c|c|c|}
\hline $\begin{array}{c}\text { Escola } \\
\text { (Integralmente ou maior parte) }\end{array}$ & $\begin{array}{c}\text { Pesquisa 1996/7 } \\
(\mathbf{\%})\end{array}$ & $\begin{array}{c}\text { Pesquisa 2003/4 } \\
(\mathbf{\%})\end{array}$ & $\begin{array}{c}\text { Pesquisa 2010 } \\
(\mathbf{\%})\end{array}$ \\
\hline Publica & 45,04 & 46,2 & 50,39 \\
\hline Privada & 54,96 & 52,9 & 49,61 \\
\hline Não se aplica & Não perguntado & 0,9 & Não perguntado \\
\hline
\end{tabular}

Quadro 8 Tipo de escola em que cursou o ensino médio cursado majoritariamente pelo estudante nos anos de 1996/7, 2003/4 e 2010.

Fonte: ANDIFES (2011, p.31).

Rev. GUAL., Florianópolis, Edição especial 2011, p.01-24. 


\section{ASPECTOS DA REESTRUTURAÇÃO DAS UNIVERSIDADES FEDERAIS POR MEIO DO REUNI - UM ESTUDO NO ESTADO DE SANTA CATARINA}

Finalmente, no que se refere à influência do REUNI, a ANDIFES (2011) apresenta em seu relatório que houve sim uma alteração nos dados em função da criação do programa. Isto se dá pelo motivo do país possuir várias universidades federais que com décadas de funcionamento, e por meio do Reuni, outras universidades federais e institutos federais foram criados, cumprindo-se assim a principal demanda do programa, que é a interiorização do ensino superior público federal.

Assim, o universo dos estudantes que participaram da pesquisa que traça o perfil do alunado em 2010 é fruto de um novo contexto, permeado pelas políticas públicas de inclusão, proporcionando de algum modo, e independente do seu impacto, um novo tecido social.

\section{CONSIDERAÇÕES FINAIS}

A sociedade passou a vislumbrar o terceiro grau como o principal meio para melhorar a condição social. Portanto, a questão do acesso ao ensino superior vem sendo discutida nas mais diversas camadas e esferas sociais. Várias foram as iniciativas tomadas, com destaque para o Plano Nacional da Educação e posteriormente o Plano Desenvolvimento Educação, em que os programas Reuni e ProUni, articulados juntamente ao FIES, UAB e os Ifes, constituíram-se nos principais pilares de sustentação para a reformulação do ensino superior brasileiro. No que se refere à Educação Superior Federal, constatou-se que o Reuni tem sido imprescindível para esta expansão de vagas e na democratização do ensino.

Analisando especificamente o estado de Santa Catarina, pôde-se comprovar que a expansão prevista está de fato ocorrendo, com um aumento visível no número de vagas. A educação superior tem sido interiorizada no estado, chegando a pessoas de regiões que até então só poderiam vislumbrar o sonho de se realizar um curso superior em uma instituição federal se fossem para outros locais.

Isto fica claro quando se analisa, sobretudo, a Universidade Federal da Fronteira Sul. Com pouco mais de um ano de fundação, a UFFS se apresenta como propulsora do progresso da região oeste do Sul do país. Algo que pode ser observado em função dos principais motivos que levaram a sua criação: a diminuição da litoralização da população; a necessidade de se trabalhar o meio ambiente na região; e o desenvolvimento da agricultura familiar.

Rev. GUAL., Florianópolis, Edição especial 2011, p.01-24. 
Além da expansão do número de vagas, pode-se constatar que o REUNI tem dado mais oportunidade às pessoas de classes economicamente desfavorecidas, conforme apresentam os relatórios da ANDIFES (2011), sinalizando o início de uma importante democratização da educação superior no Brasil.

O Brasil, que pode tornar-se $5^{\mathrm{a}}$ potência econômica mundial na próxima década ${ }^{\mathrm{ii}}$, que pretende aumentar sua posição no ranking do Índice de Desenvolvimento Humano e aumentar seu Produto Interno Bruto, além de diminuir as taxas de desemprego, deve criar mais vagas no ensino superior além de expandir a democratização do acesso à educação superior, pois o ensino superior será a força motriz que impulsionará o país para o desejado desenvolvimento.

Cabe agora ao Governo Federal prosseguir com a criação e o desenvolvimento de programas públicos eficazes para acelerar o progresso, que, de acordo com os dados apresentados, já está acontecendo. É necessário que a educação seja protagonista dessas políticas públicas, para que a nação seja por ela transformada, e dessa forma, o tão almejado desenvolvimento econômico e social seja alcançado.

\section{REFERÊNCIAS}

ANDIFES. Relatório de Acompanhamento do Programa de Apoio a Planos de Reestruturação e Expansão das Universidades Federais (Reuni). Brasília. 2010.

Perfil Sócioeconômico e Cultural dos Estudantes de Graduação das

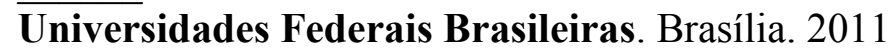

BRASIL. Lei No 9.394/96, de 20 de dezembro de 1996. Lei de Diretrizes e Bases da Educação Nacional. Diário Oficial da União, Brasília, DF, 23 dez. 1996.

. Lei ${ }^{\circ} 10.172$, de 9 de janeiro de 2001. Aprova o Plano Nacional de Educação e dá outras providencias. Diário Oficial da União. Brasília, DF, 10 jan. 2001.

. Decreto $n^{0}$ 6.096, de 24 de abril de 2007. Institui o Programa de Apoio a Planos de Reestruturação e Expansão das Universidades Federais - REUNI. Brasília, 2007.

. Ministério da Educação. INEP. O Plano de desenvolvimento da educação: razões, princípios e programas. Brasília: $2007 \mathrm{~b}$.

CANUTO, Vera Regina Albuquerque. Políticos e Educadores: a organização do ensino superior no Brasil. Petrópolis: Editora Vozes, 1987. 
GRACIANO, Mariângela; HADDAD, Sérgio. Educação: Direito Universal ou Mercado em Expansão?. Revista São Paulo em Perspectiva, Mar. 2004.

GIL. Métodos e Técnicas de Pesquisa Social. São Paulo: Atlas, 1995.

INEP. Dados finais do Censo da Educação Superior 2008. Brasília. 2009.

INPEAU. Instituto de Pesquisas e Estudos em Administração Universitária: Objetivos. Florianópolis. 2011. Disponível em $<$ http://www.inpeau.ufsc.br/wp/?page_id=8>. Acesso em: 12 de Fevereiro de 2011.

LÉDA, Denise Bessa; MANCEBO, Deise. Reuni: heteronomia e precarização da universidade e do trabalho docente. Revista Educação \& Realidade, Porto Alegre, v.34, p.4964, jan./abr. 2009.

LOUREIRO, Maria Amélia Salgado. História das universidades. São Paulo: Estrela Alfa Editora, 1986.

MEC. REUNI - Reestruturação e Expansão das Universidades Federais Brasileiras. Brasília. 2010. Disponível em: <http://reuni.mec.gov.br>. Acesso em: 22 de Maio de 2010.

OAB. História. Disponível em <http://www.oabcascavel.org.br/institucional/historia/>. Acesso em 15 de Outubro de 2011.

PINTO, J. M. R.. Financiamento da educação no Brasil: um balanço do governo FHC (1995-2002). Educação e Sociedade, Campinas, v. 23, n. 80, p. 109-136, 2002.

RICHARDSON, R. J. Pesquisa Social: Métodos e Técnicas. São Paulo: Atlas, 1999.

ROMANELLI, Otaíza de Oliveira. História da Educação no Brasil (1930/1973). 14 Edição. Petrópolis: Editora Vozes, 1991.

SILVA, Rosimeri Carvalho. A Prática da Extensão Universitária: um estudo de caso na Universidade Federal de Santa Catarina. Florianópolis, 1991. Dissertação (Mestrado em Administração) - Curso de Pós-Graduação em Administração CPGA/CSE, Universidade Federal de Santa Catarina, 1991.

SCHWARTZMAN, Simon. A sociedade do conhecimento e a educação tecnológica. São Paulo: Serviço Nacional de Aprendizagem Industrial - SENAI. Jan 2005.

SELLTIZ et. al. Métodos de pesquisa nas relações sociais. São Paulo: EPU, 1974.

TEIXEIRA, Anísio. Educação Superior no Brasil: análise e interpretação de sua evolução até 1969. Rio de Janeiro: Editora da Fundação Getúlio Vargas, 1989. 
UFCG. Plano de Expansão Institucional - Planexp. Campina Grande. 2010. Disponível em $<$ http://www.ufcg.edu.br/ spe/pjustificativa.htm>. Acesso em: 10 de Novembro de 2010.

UFFS. A Instituição. Chapecó. 2010. Disponível em

$<$ http://www.uffs.edu.br/index.php?option=com_content\&view=article\&id=90\&Itemid=244> . Acesso em: 10 de Novembro de 2010.

UFSC. Projeto Reuni UFSC - Encaminhado ao MEC. Florianópolis. 2010. Disponível em $<$ http://www.reuni.ufsc.br/site/arquivos/3842_projeto\%20reuni.pdf $>$. Acesso em: 17 de Junho de 2010.

Missão da UFSC. Florianópolis. 2010b. Disponível em $<$ http://antiga.ufsc.br/paginas/missao.php $>$. Acesso em: 10 de Novembro de 2010. YIN, R. K. Case study research: design and methods. Beverly Hills: Sage, 1989.

\footnotetext{
' Os dados utilizados para se encontrar a taxa de 13,7\% dos jovens matriculados no Ensino Superior foram os do Censo da Educação Superior de 2008 (divulgados em 27 de Novembro de 2009) tendo em vista que os dados do Censo da Educação Superior de 2009 ainda não estão disponíveis

ii FONTE: “O Brasil decola.”. Reportagem da Revista The Economist, em 12 de Novembro de 2009.
}

Rev. GUAL., Florianópolis, Edição especial 2011, p.01-24. 


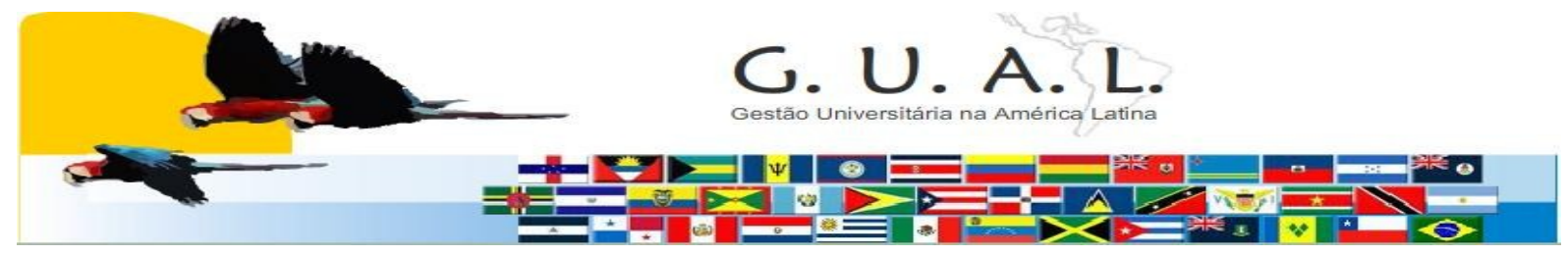

ISSN 1983-4535

\title{
ASPECTS OF THE RESTRUCTURING OF FEDERAL UNIVERSITIES BY REUNI - A STUDY IN THE STATE OF SANTA CATARINA
}

\author{
Danilo de Melo Costa, Master \\ Centro Universitário UNA \\ danilo_mcosta@yahoo.com.br \\ Alexandre Marino Costa, Doctor \\ Universidade Federal de Santa Catarina - UFSC \\ marino@cse.ufsc.br
}

\author{
Cláudio José Amante, Doctor \\ Universidade Federal de Santa Catarina - UFSC \\ cjamante@reitoria.ufsc.br
}

Cláudio Heleno Pinto da Silva, Bachelor

Instituto Federal do Sudeste de Minas Gerais IFSMG

claudiohps@gmail.com

\begin{abstract}
The Brazilian Federal Universities are facing a major transformation that occurs through its restructuring and expansion. New universities and new campuses in universities that already existed are now present in all units of the federation. In the state of Santa Catarina, this growth is guided with the restructuring of the Federal University of Santa Catarina, by means of Reuni, and the creation of the Federal University of Southern Frontier, founded in the range of the program. Therefore, this article attempted to analyze the main aspects of this restructuring in the state of Santa Catarina. For this purpose, was realized an exploratory and qualitative research. To collect and analysis of data, were used reports from MEC, INEP, ANDIFES, laws, decrees and material already published that addressed this subject. In addition, interviews were realized with the Deans of the institutions studied. The results showed that the expansion of the federal universities have, in fact, happened, and in Santa Catarina, this phenomenon was confirmed. Besides the expansion of the number of sits, it was found that Reuni has given more opportunities to people for economically disadvantaged classes, signaling the beginning of an important democratization of higher education in Brazil.
\end{abstract}

Keywords: Reuni. UFSC. UFFS. Higher Education. Expansion. 